AperTO - Archivio Istituzionale Open Access dell'Università di Torino

\title{
Risk Attitudes and Preferences for Redistribution: New Evidence from the Lab
}

\section{This is the author's manuscript}

Original Citation:

Availability:

This version is available http://hdl.handle.net/2318/1657976

since 2018-01-18T14:45:39Z

Published version:

DOI:10.1093/cesifo/ifx022

Terms of use:

Open Access

Anyone can freely access the full text of works made available as "Open Access". Works made available under a Creative Commons license can be used according to the terms and conditions of said license. Use of all other works requires consent of the right holder (author or publisher) if not exempted from copyright protection by the applicable law. 


\title{
Risk Attitudes and Preferences for Redistribution: \\ New Evidence from the Lab*
}

\author{
Matteo ASSANDRI \\ (University of Torino - Department ESOMAS) \\ Anna MAFFIOLETTI \\ (University of Torino - Department ESOMAS) \\ Massimiliano PIACENZA* \\ (University of Torino - Department ESOMAS)
}

Gilberto TURATI

(Catholic University, Rome - Department of Economics and Finance)

This version: November 27, 2017

\begin{abstract}
Although preferences for redistribution have been widely studied in the economic literature, their relationship with risk preferences has received only marginal attention so far. The aim of this work is to provide evidence on this topic using a between-subject laboratory experiment and a fine grid to measure individual risk-attitudes. Our findings suggest that the more people are risk averse, the more they are in favor of redistribution across members of a society that allows upward social mobility, but it is also characterized by uncertainty about the final position in the income ladder. Our interpretation is that individuals exploit redistributive taxation as a form of insurance against uncertainty in the outcome of their effort.
\end{abstract}

JEL Codes: C91, D81, H24, H30

Keywords: preferences for redistribution, risk attitudes, social mobility, uncertainty

\footnotetext{
* We wish to thank two anonymous referees for their careful review of the first draft of the paper, and the Editor Paola Profeta for her advices. Thanks are also due to Stephanie Armbruster, Michele Bernasconi, and all seminar participants at the 2016 EPCS Meeting (University of Freiburg), the 2016 LabSi Lab2 Workshop (Second University of Naples), and the 2016 SIEP Conference (University of Salento), for their insightful comments. Financial and technical support from the School of Management and Economics (University of Torino) is gratefully acknowledged. Usual disclaimer apply.

* Corresponding author: Department of Economics, Social Sciences, Applied Mathematics and Statistics (ESOMAS), University of Torino, School of Management and Economics, Corso Unione Sovietica 218 bis, 10134 Torino, Italy. Phone: +39.011.6706188 - Fax: +39.011.6706062 - E-mail: massimiliano.piacenza@unito.it.
} 


\section{Introduction}

The economic literature has widely studied the topic of preferences for redistribution by means of field studies and laboratory experiments, analyzing the potential role of many determinants: from fairness and efficiency concerns to cultural attitudes, from political institutions to racial fragmentation (e.g., Beckman et al., 2004; Alesina and Giuliano, 2011). However, the role of individual risk attitudes has received so far little attention, despite their obvious importance for understanding the heterogeneous support for redistribution policies in real-world economies, usually characterized by some degree of uncertainty about individual future income. For instance, people may rationally consider that they, or their children, may better their position in the income distribution over time; hence, they vote today for less redistribution (the wellknown Prospect Of Upward Mobility, or POUM, hypothesis, from Benabou and Ok, 2001). However, future incomes are by definition risky: people are not sure both on the real outcomes of their effort to climb the income ladder, but also on the tax rules that would be in force in the future. In the presence of a high uncertainty about ones' future income, risk averse individuals may well decide to support more redistribution as a form of insurance against possible future negative shocks. Hence, individual risk attitudes should play a role in shaping preferences toward redistribution.

The first references to risk attitudes in the context of redistribution are due to Rawls (1971) Veil of Ignorance and the following experimental test proposed by Beck (1994) that provided little evidence that individuals may favor a more equal income distribution if they are more riskaverse. However, one limit of this study was in the design, which considered the choice of lotteries as the unique determinants of participants' final payoffs, without accounting for the possibility of upward mobility via individual effort, as it happens in real-world societies. More recently, only Durante et al. (2014) have incidentally explored the issue, by designing a laboratory experiment that explicitly considers both individual risk attitudes and costly effort in the analysis. Preferences for redistribution are elicited in a context where rules determining the income distribution vary from completely random to completely linked to individual effort. The authors show that the riskier the income determination rule, the higher the demand for redistribution. However, Durante et al. (2014) focus on the impact of individual perception of social fairness on preferences for redistribution, and just consider risk attitudes among control variables in their analysis. Unsurprisingly, the elicitation mechanism is rough, and coefficients for risk-attitudes are often not statistically significant and contradictory in sign. 
The purpose of our study is to provide evidence on the role of risk attitudes in shaping preferences for redistribution, by designing a laboratory experiment with two main characteristics: first, we exploit a pure between-subject design, which allows us to avoid potential confounding effects driven by moral concerns when studying the relationship between risk preferences and the demand for redistributive taxation; second, we elicit preferences using a grid that allows a precise measurement of individual risk-attitudes.

The remainder of the paper is structured as follows. The experimental design and its practical implementation are presented in Section 2. Section 3 discusses the results, showing the evidence from both mean comparisons across treatments and regression analysis. Section 4 provides concluding remarks.

\section{Experimental design and implementation}

Our experiment has been designed to specifically analyze the relationship between individual risk attitudes and preferences for redistribution. We aim at testing whether more risk averse individuals exhibit stronger preferences for income redistribution, especially when they are asked to make their choices in environments characterized by high uncertainty about their final positions in the income ladder.

In particular, to pursue our goal, we set up a framework in which we first elicit risk attitudes of subjects and, second, after assigning an initial endowment, we ask participants to take part in a real effort task that allows them to improve their initial income, while at the same time deciding the desired level of taxation. In this way, they will reveal their preferences for redistribution in a society that allows upward social mobility. More in details, the participants are asked to select their ideal rate $t_{i}^{*}$ of a (very simple) purely redistributive proportional income tax, where tax revenues are then equally shared among all individuals $(N)$. Subjects' after-tax income $Y^{a t}$ is defined according to Eq. [1]:

$$
Y_{i}^{a t}=\left(y+y_{i}^{e}\right)\left(1-t^{*}\right)+\frac{1}{N} \sum_{i}\left(y+y_{i}^{e}\right) t *
$$

where $y$ is the initial exogenous income (the same for all the participants), $y_{i}^{e}$ is the incremental income that can be gained by individual $i$ exercising effort $e$, and $t^{*}$ is the chosen tax rate to be applied to all subjects. To avoid strategic responses, we select $t^{*}$ according to the random dictator 
rule, randomly extracting a rate from all the values $t_{i}^{*}$ chosen by the participants. ${ }^{1}$ Hence, the role of participants' average income is pivotal in our framework: everyone with a final gross income $\left(y+y_{i}^{e}\right)$ above the mean is a net taxpayer (i.e., she pays more taxes than the transfer she receives), while the opposite is true for the subjects with incomes below the mean (i.e., they are net recipients). Moreover, the threshold average income is unknown a priori since it depends on both the common initial exogenous income and the additional (endogenous) incomes associated to individual choices of effort level; this introduces some uncertainty about subjects' future income.

As the main purpose of our study is not to check the stability of individual preferences (for which a within-subject design would be required), but to investigate the possible variations in the average demand for redistribution driven by different risk attitudes and the exposure to environments characterized by different (exogenous) risk levels, we used a between-subject design, where each individual is exposed to only one treatment; thus, we avoid carry-over and experimenter demand effects. $^{2}$ In particular, the behavioral hypotheses tested in our experiment are the following:

a) risk-attitudes affect preferences for redistribution. In particular, we expect that more risk averse individuals demand more redistribution, choosing a higher tax rate;

b) the riskiness of the economic environment matters for redistribution. In particular, risk averse individuals are expected to prefer more redistribution when they face a partially random reward for their effort with respect to a situation in which effort reward is sure.

Here the underlying assumption is that risk averse individuals may prefer a higher degree of redistribution in face of higher uncertainty, in order to insure themselves against potentially higher income losses; and this increase in the demand for redistribution should be higher for individuals characterized by a higher degree of risk aversion. The experiment took place at the School of Management and Economics of the University of Torino, on October $7^{\text {th }}, 2015$. Subjects were recruited by means of a leaflet distributed among students of Business and Economics classes, both at undergraduate and graduate level. We ran two sessions - each of which lasted about two hours - with a total of 39 participants, using two different treatments: a first treatment in which the reward of the effort was perfectly known by subjects (Session 1 certain effort reward, 20 subjects); and a second treatment in which the reward of the effort was

\footnotetext{
1 This experimental setup is similar to that adopted in the recent studies by Durante et al. (2014) and Beraldo et al. (2014).

${ }^{2}$ For a throughout discussion of merits and limits of the two types of experimental design and the choice of the more appropriate approach see Charness et al. (2012).
} 
partially randomly determined (Session 2 - uncertain effort reward, 19 subjects); the aim of the second treatment is to simulate a more risky economic environment, where the outcomes of social mobility are even more uncertain in terms of final income. Each session was organized in three parts. In part A, we elicited individual risk preferences, by asking subjects to choose between a lottery and different certain amounts of money. In part B, subjects decided the number of exercises to be solved when performing the effort task and chose their preferred tax rate. Part C was a brief survey in which subjects were asked some personal data like sex and age, and their opinions on the perceived social mobility and individual beliefs about the source of income inequalities. After subjects entered the room, general instructions were read aloud, leaving opportunities for questions. The structure of the experiment was then explained, as well as the decision sequence and the computation of final rewards. Participants were also informed that during the whole experiment an ad-hoc currency named "token" had to be used, and the conversion rate for the actual payment was set at 1 token $=0.01$ Euros for the risk aversion test and 1 token $=0.03$ Euros for the redistribution game. The higher payment on the redistribution game was set in order to place higher monetary incentives on this part of the experiment, so as to stimulate in the subjects the perception of social mobility and observe enough variability in effort and tax rate preferences. Subjects' earnings, determined according to their performance in the two tasks of the experiment (risk aversion test and redistribution game), were paid in cash at the end of each session. ${ }^{3}$ The time sequence of different tasks and decisions is represented in Figure 1. Below we will discuss the main features of the first two parts of the experiment, while detailed instructions and the whole set of survey questions are reported in the Appendix.

\footnotetext{
3 The average payment was 3.52 Euros, with and a minimum of 0.85 Euros and a maximum of 5.69 Euros. There was also a coffee bonus for showing up as a reserve. We are aware of the fact that the stakes the participants face in our experiment are smaller than in other similar studies. However, adopting the Reward Dominance criterion proposed by Alm and Jacobson (2007), these rewards, even if small, may be considered large enough to be able to offset subjective costs that individuals place on the participation in the experiment. First, students are likely to have quite low opportunity costs, even more so since $80 \%$ of the students were already planning to visit the School where the experiment was taking place to attend already scheduled lectures. Second, monetary incentives were framed in term of tokens, hence subjects has to deal with numbers higher than final actual payments. Third, the literature on incentive mechanisms has shown that average subjects' responses do not change substantially with the size of payments, but there is a higher variance in the answers when low monetary incentives are used (e.g., Smith and Walker, 1993; Camerer and Hogarth, 1999).
} 
Figure 1. Time sequence of experimental tasks and decisions

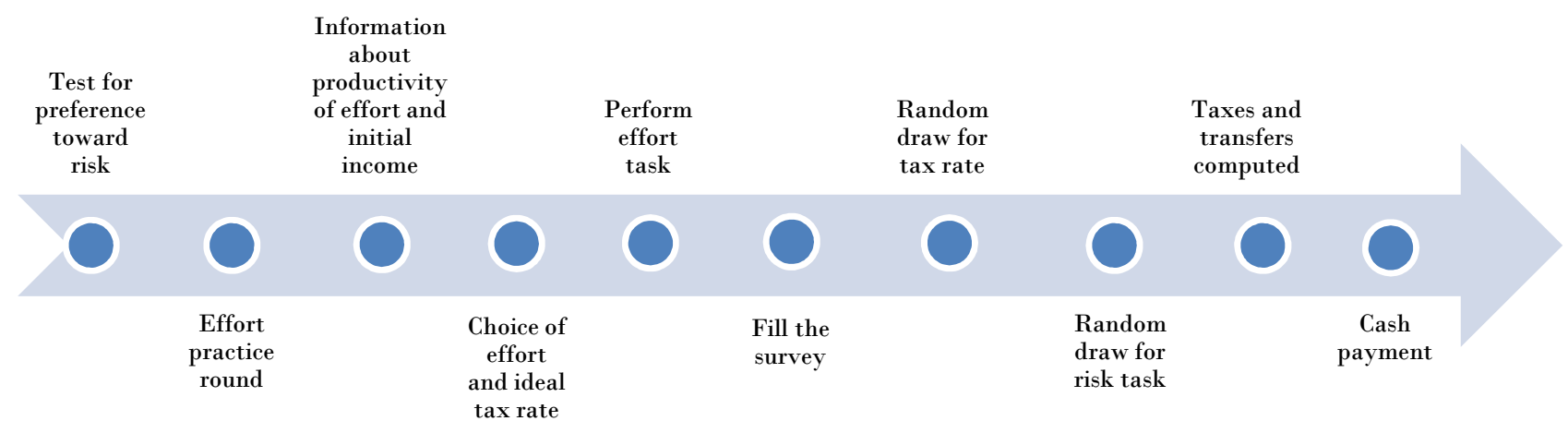

\subsection{Risk aversion test}

The first part of experiment (Part A) is related to testing subjects' risk preferences. This part was the same for both treatments and is crucial to our experiment, given our behavioral hypotheses discussed above. As a method of elicitation of risk preferences we used a version of the Multiple Price List method originally proposed by Holt and Laury (2002). In particular, the version applied here is the approach used, e.g., in Dohmen et al. (2010) and discussed in Abdellaoui (2011), which relies on a longer list of options to choose from (20 instead of 10), thus allowing a finer assessment of risk attitudes. The risk aversion test involves choices between a safe amount and a lottery (Table 1) and it is easy to understand and to implement in a paperand-pencil context. The number of tokens shown in Table 1 is of the same order of magnitude of the tokens that subjects face during the second part of the experiment. Specifically, the expected value of the lottery in Column B (75) was fixed to the average between the lowest and the highest number of tokens we expected people may have to deal with in the redistribution game.

Column A in Table 1 reports a safe amount of tokens that increases from row to row, while Column B shows a lottery with which the subject can either win 150 tokens or nothing with equal probability, and it is the same in each row. Subjects were asked to choose between Column A and Column B starting from the first row to the last row. For the first row, choosing Column B is the rational choice. At some point, however, subjects are expected to switch to Column A; and risk loving subjects will switch later than risk averse ones. More precisely, subjects that decide to stop choosing the lottery exactly at row 16 are classified as risk neutral, since the certain equivalent is just equal to the expected value of the lottery, while those switching before (after) row 16 are classified as risk averse (loving). It is worth highlighting that this procedure allowed us to assess on a 1-20 scale participants' risk attitudes, thus obtaining a 
more precise measure of risk aversion (due to the finer grid) than, e.g., in Durante et al. (2014) and Gärtner et al. (2017), where risk attitudes were evaluated using a less refined scale. ${ }^{4}$

Table 1. The risk aversion test

\begin{tabular}{|c|c|c|cc|}
\hline Row & Column A & Column B & \multicolumn{2}{|c|}{ Choice } \\
\hline 1 & 0 tokens & $50 \% 150$ tokens $-50 \% 0$ tokens & A & B \\
\hline 2 & 5 tokens & $50 \% 150$ tokens $-50 \% 0$ tokens & A & B \\
\hline 3 & 10 tokens & $50 \% 150$ tokens $-50 \% 0$ tokens & A & B \\
\hline 4 & 15 tokens & $50 \% 150$ tokens $-50 \% 0$ tokens & A & B \\
\hline 5 & 20 tokens & $50 \% 150$ tokens $-50 \% 0$ tokens & A & B \\
\hline 6 & 25 tokens & $50 \% 150$ tokens $-50 \% 0$ tokens & A & B \\
\hline 7 & 30 tokens & $50 \% 150$ tokens $-50 \% 0$ tokens & A & B \\
\hline 8 & 35 tokens & $50 \% 150$ tokens $-50 \% 0$ tokens & A & B \\
\hline 9 & 40 tokens & $50 \% 150$ tokens $-50 \% 0$ tokens & A & B \\
\hline 10 & 45 tokens & $50 \% 150$ tokens $-50 \% 0$ tokens & A & B \\
\hline 11 & 50 tokens & $50 \% 150$ tokens $-50 \% 0$ tokens & A & B \\
\hline 12 & 55 tokens & $50 \% 150$ tokens $-50 \% 0$ tokens & A & B \\
\hline 13 & 60 tokens & $50 \% 150$ tokens $-50 \% 0$ tokens & A & B \\
\hline 14 & 65 tokens & $50 \% 150$ tokens $-50 \% 0$ tokens & A & B \\
\hline 15 & 70 tokens & $50 \% 150$ tokens $-50 \% 0$ tokens & A & B \\
\hline 16 & 75 tokens & $50 \% 150$ tokens $-50 \% 0$ tokens & A & B \\
\hline 17 & 80 tokens & $50 \% 150$ tokens $-50 \% 0$ tokens & A & B \\
\hline 18 & 85 tokens & $50 \% 150$ tokens $-50 \% 0$ tokens & A & B \\
\hline 19 & 90 tokens & $50 \% 150$ tokens $-50 \% 0$ tokens & A & B \\
\hline 20 & 95 tokens & $50 \% 150$ tokens $-50 \% 0$ tokens & A & B \\
\hline
\end{tabular}

As noted before, part of the subject's final payment is related to her performance in this task. In each session, one of the 20 rows in Table 1 was randomly selected at the end of the experiment and the choice made by participants in that row was paid, allowing each subject to individually play the lottery in Column B if necessary. Suppose, for instance, that at the end of the experiment, row 7 is the outcome of the random draw from an urn with numbers from 1 to 20 . If in that row a subject's choice was A, she will receive the amount of Euros corresponding to 30 tokens; if instead a subject's choice was B, she will play the lottery by throwing a die and will win 0 tokens if the outcome is 1,2 or 3 and 150 tokens if the outcome is 4, 5 or 6 .

\footnotetext{
${ }^{4}$ Indeed, Durante et al. (2014) used a 1-5 scale and Gärtner et al. (2017) a 1-8 scale. Moreover, the assessment of risk preferences in Gärtner et al. (2017), unlike the incentivized risk attitude measures elicited in the laboratory, suffers also the limit to rely on a survey approach, where respondents face hypothetical choices between a lottery and a safe value and do not receive any monetary payment for their performance in the test.
} 


\subsection{Choice of effort and the preferred tax rate}

The second part of the experiment (Part B) involved the participants in an "effort" task and the tax rate decision. As for the "effort" task, our idea was to let subjects feel that additional income $y_{i}^{e}$ in equation [1] was non-trivially earned; that is to say, to feel that effort was really costly. In our experimental setting, such cost was interpreted as a time-consuming activity that required some ability to be performed. The effort task chosen here was proposed, e.g., by Buch and Engel (2012) and has the appealing feature of being easy to administer in a paper-andpencil experiment, but also complex enough to require people to exert real effort in order to perform it. It consisted in finding how many couples of numbers added up to 10 in $4 \times 4$ tables, an example of which is represented in Table 2. Each table had at least one couple adding up to 10 , and at most four. The size of the tables was chosen in order to make the task as challenging as possible, and 4x4 was the maximum size presented to subjects in Buch and Engel (2012).

Table 2. Example of effort task

\begin{tabular}{|l|l|l|l|}
\hline 2.15 & 4.19 & $\mathbf{3 . 2 2}$ & 6.01 \\
\hline 8.02 & $\mathbf{6 . 7 8}$ & 1.08 & 4.05 \\
\hline 1.01 & 7.54 & 4.93 & 9.99 \\
\hline 2.02 & 5.68 & 4.33 & 1.69 \\
\hline
\end{tabular}

In order to allow subjects to correctly understand the task and their abilities in solving the exercises, first, subjects were given ten minutes to practice over the task with 10 tables. At the end of this practice round, solutions were shown to allow participants to self-assess their performance and their productivity in the task. At this point, information about the initial income (equal for all participants) and the reward associated to effort was displayed, and each subject had to decide simultaneously both the level of effort and the desired tax rate.

Each subject was asked to commit to solve a number between zero and 25 exercises. In the baseline treatment (Session 1), subjects knew that each exercise they solved would have contributed deterministically to increase their final income by 2 tokens. In order to make the task even more challenging, the commitment was for the number of correctly solved exercises $\left(n^{e}\right)$; hence, subjects were not allowed to leave the room until they correctly solved the number they had chosen, and the number of additional tokens generated by the effort was computed as $y^{e}=n^{e} \times 2$. In the second treatment (Session 2), the link between effort and reward became uncertain, since reward now can vary between 1 to 2 tokens. When all subjects solved the number of exercises they have committed to, a random number $p$ between 0.5 and 1 - with 
increments of 0.1 - was drawn by each subject, and the actual number of tokens produced by her effort was then computed as $y^{e}=n^{e} \times 2 \times p .^{5}$

While committing to a desired level of effort, participants had also to choose their preferred income tax rate $t^{*}$, under the rule that the whole amount of fiscal revenues had to be equally divided among all participants. We allowed subjects to choose between values of $t^{*}$ ranging from zero to $100 \%$, limiting internal options to those defined by $10 \%$ increases between the two extremes (i.e., $10 \%, 20 \%, \ldots, 90 \%$ ). At the end of the experiment, an extraction from an urn was made in order to determine the actual tax rate $t^{*}$ defined by the random dictator rule and each subject was paid the after-tax income $Y_{i}^{a t}$ according to Eq. [1].

Let us make a simple numerical example to illustrate the mechanism determining final payoffs: suppose there are only two participants, Mrs. 1 and Mrs. 2. Their initial income $y$ is equal to 100 tokens (the same used in the experiment). Mrs. 1 commits herself to solve 10 exercises, while the effort of Mrs. 2 is 20 exercises. If they are playing in Session 1, their final income is given by their initial income plus $10 \times 2$ tokens (the effort reward) for Mrs. 1 and $20 \times 2$ tokens for Mrs. 2 . Hence, the final gross income $\left(y+y^{e}\right)$ is 120 for Mrs. 1 and 140 for Mrs. 2. Assuming that preferred tax rates are $50 \%$ and $30 \%$ for Mrs. 1 and 2, respectively, and that, under the random dictator rule, an actual tax rate $t^{*}=50 \%(30 \%)$ had been chosen, Mrs. 1 is paying $60(36)$ as a tax, while Mrs. 2 is paying 70 (42). Total tax revenue are then 130 (78) and each subject receives a transfer of 65 (39), leaving final after-tax income $Y^{a t}$ for Mrs. 1 at 125 (123) tokens and for Mrs. 2 at 135 (137) tokens. Hence, Mrs. 1 is a net recipient, while Mrs. 2 a net taxpayer.

\section{Results}

In this section we discuss our findings, concentrating on the role that risk preferences and the riskiness of the economic environment play in shaping individual preferences for redistribution. In particular, in presenting our experimental findings, we start by discussing some descriptive statistics for risk attitudes (Section 3.1) and the preferred degree of redistribution (Section 3.2.1); we then focus on the relationship between the two variables in Section 3.2.2. As a premise for the discussion of results, one can notice from Table 2 that the participants' characteristics in terms of gender, age and level of education appear to be roughly balanced

\footnotetext{
5 In the survey carried out at the end of the experiment, we also asked the participants whether they found difficulties in solving the exercises. The answers provided comforting information, since the task was perceived as hard but not too hard by the subjects: on a 1-5 scale (where 1 is extremely easy and 5 extremely difficult) the average response was 2.4 and no subject chose 5 . The practice round of the design, that allowed the participants to familiarize with effort task, was also assessed as useful, since only $10 \%$ of students reported to have overestimated the number of exercises they were ready to solve.
} 
across the two sessions, thus supporting the comparability of the choices made by subjects under different treatments.

Table 2. Characteristics of participants by treatment

\begin{tabular}{|c|c|c|c|c|}
\hline & \multicolumn{2}{|c|}{$\begin{array}{c}\text { Session } 1 \\
\text { (certain } \text { effort reward) } \\
N=20\end{array}$} & \multicolumn{2}{|c|}{$\begin{array}{c}\text { Session } 2 \\
\text { (uncertain effort reward) } \\
N=19\end{array}$} \\
\hline & Mean & St. Dev. & Mean & St. Dev. \\
\hline Female $(\%)$ & 0.55 & 0.51 & 0.58 & 0.51 \\
\hline Age & 22 & 1.60 & 22 & 2.57 \\
\hline Undergraduate (\%) & 0.70 & 0.47 & 0.63 & 0.50 \\
\hline
\end{tabular}

\subsection{Measuring risk attitudes}

In order to analyze the relationship between preferences for redistribution and risk attitudes, a precise measure of risk attitudes is needed. The measure we consider here is defined according to the number of times the subject selected the lottery over the certain amount in the risk aversion test: the more risk averse the participant, the lower the number of rows the subject needed in order to stop choosing the lottery. As a consequence, the higher the value of the variable, the lower the degree of risk aversion. We call this risk attitude measure RISK_LOVE accordingly. A critical issue to assess the validity of experimentally measured risk preferences is the degree to which subjects were able to understand the task. Given the structure of the Multiple Price Lists, any rational individual who understood the instructions would switch column only once, multiple switches denoting the inability of understanding the problem at hand. In the Holt and Laury (2002) experimental session most comparable with our test (i.e., the one with very low and hypothetical stakes), roughly $10 \%$ of subjects did not understand the task and submitted contradicting answers; a comparable share was found in our data (six subjects, corresponding to about $15 \%)$. It is also worth to mention that some subjects in the original Holt and Laury (2002) experiment switched in the first or in the last row, exhibiting quite extreme attitudes toward risk: these subjects were considered by the authors among those who did not understand the instructions. This pattern of extreme choices was not present in our test. Looking at our data, the majority of subjects who switched more than once (one student in Session 1 and three students in Session 2) displayed a clear pattern of choices, and it was possible to define a narrow "switching area" instead of a precise switching point. As far as these students were concerned, it was still possible to estimate their risk attitudes as the average of the switching area. Only two 
subjects in Session 2 exhibited a pattern of choices that did not allow us to estimate a measure for their risk attitudes, hence we dropped these individuals from the analysis and the discussion of results that follows refer to a reduced sample of 37 subjects.

Considering now the risk attitudes recorded during the experiment, all the participants displayed risk aversion or risk neutrality: our RISK_LOVE variable ranges from 3 to 16 , with a mean of 9.5 and a standard deviation of 3.7. Risk loving subjects are rare to find in experiments, even though in Holt and Laury (2002) a small share of subjects (about 6\%) were classified as such. The difference with respect to our results may be due to the fact that students of Business and Economics are likely to be more acquainted with the computation of the expected value of a lottery than students with a different background. ${ }^{6}$ Focusing on gender differences in risk attitudes, we find that females are slightly more risk averse than males (average $R I S K \_L O V E$ is equal to 8.8 and 10.3 , respectively), but the difference between means is not statistically significant according to a non-parametric Mann-Whitney test $(\mathrm{p}=0.25)$. Thus, our data does not support the main evidence in the experimental literature that gender matters for risk attitudes and female are in general more risk averse than males (e.g., Croson and Gneezy, 2009). However, some recent research on the topic by Crosetto and Filippin (2013) has pointed out that women may seem more risk averse than men because they are indeed more loss averse, and the majority of the existing tests are not able to disentangle the two forces at stake. ${ }^{7}$ As for the variability of risk attitudes across the two sessions, the distribution of RISK_LOVE is quite stable: the mean ranges from 9.1 (st. dev. 3.5) in Session 1 to 9.9 (st. dev. 4) in Session 2 and the difference between treatments is not statistically significant according to the Mann-Whitney test $(p=0.53)$. Moreover, the median and the third quartile are almost equal in the two treatments (9.5/11.8 in Session 1 vs. 10/12.5 in Session 2), which highlights that in both scenarios the percentage of risk-averse subjects is significantly greater than the percentage of risk-neutral subjects. Notice that the fact that the distribution of the elicited risk attitude measures - as well as of the other individual features (Table 2) - is similar across the two scenarios is crucial for the test on the difference in the preferences for redistribution between the

\footnotetext{
6 It should also be noted that most experimental tests dealing with establishing the best method to elicit risk preferences through lotteries use stakes different from those of our experiment. In particular, only Holt and Laury (2002) adopt a lottery comparable with our design. For a general discussion of the different methods to elicit risk preferences see Crosetto and Filippin (2016).

${ }^{7}$ Notice also that the original Holt and Laury (2002) Multiple Price Lists approach is unlikely to be affected by the loss aversion problem and the results about gender differences are contradictory when their test is used to measure risk attitudes. Moreover, in our study we exploit the extended version of this approach by Dohmen et al. (2010) that provides less clear reference points for the subjects and hence should avoid even more potential confounding effects due to loss aversion.
} 
'certain effort reward' treatment and the 'uncertain effort reward' case (see Section 3.2.1). Comparability makes subjects in the two scenarios as sampled from the same population, hence making comparisons reliable.

\subsection{Preferences for redistribution}

Looking at choices of the preferred degree of redistribution, the average tax rate $t^{*}$ computed over the two sessions is $25 \%$ (standard deviation 0.28 ). The value is considerably lower than those found in some recent studies (e.g., Durante et al., 2014; Beraldo et al., 2014), since $t^{*}$ in comparable treatments, was around $39 \%$. There are two possible explanation for this difference: one is related to the specificities of our sample, entirely composed by students of Business and Economics, who are likely to be driven more by self-interested motivations than students with a different background. The second explanation is related to the lower stakes in our experiment, as subjects might have anticipated the low final payment, and tried to increase the net payment as much as possible. Interestingly, women seem to prefer lower levels of redistribution with respect to men (19\% vs. $34 \%)$, even if the Mann-Whitney test rejects the null hypothesis only at $10 \%$ level of significance $(p=0.09)$, requiring further investigation on these gender issues via multivariate regression analysis in order to control for possible confounding factors.

\subsubsection{Comparison of average tax rates across treatments}

According to our behavioral hypotheses, risk-averse subjects (the majority in both sessions) are expected to react to changes in the treatment (certainty/uncertainty in rewarding effort) by selecting different tax rates $t^{*}$. In other words, we expect individuals to ask for more or less redistribution depending on the probability of social mobility, which is linked to the degree of uncertainty of their position in the final income distribution (i.e., their final monetary payoff). The idea is that redistributive taxation can be used as a form of insurance and, consequently, the higher a subject's risk aversion, the higher its desired level of $t^{*}$, and the stronger its reaction in terms of increasing $t^{*}$ when moving from a certain to an uncertain reward for effort. From Figure 2, exploiting the between-subject nature of the design, one can see that the average $t^{*}$ chosen by individuals across sessions seem to confirm our expectations, since the average $t^{*}$ increases (from 19\% to $32 \%$ ) when uncertainty about the reward of their effort is introduced. This evidence support the view that people are likely to exploit the redistribution as an insurance mechanism against potentially negative outcomes in the final income distribution. 
Figure 2. Average tax rate selected by subjects in each session

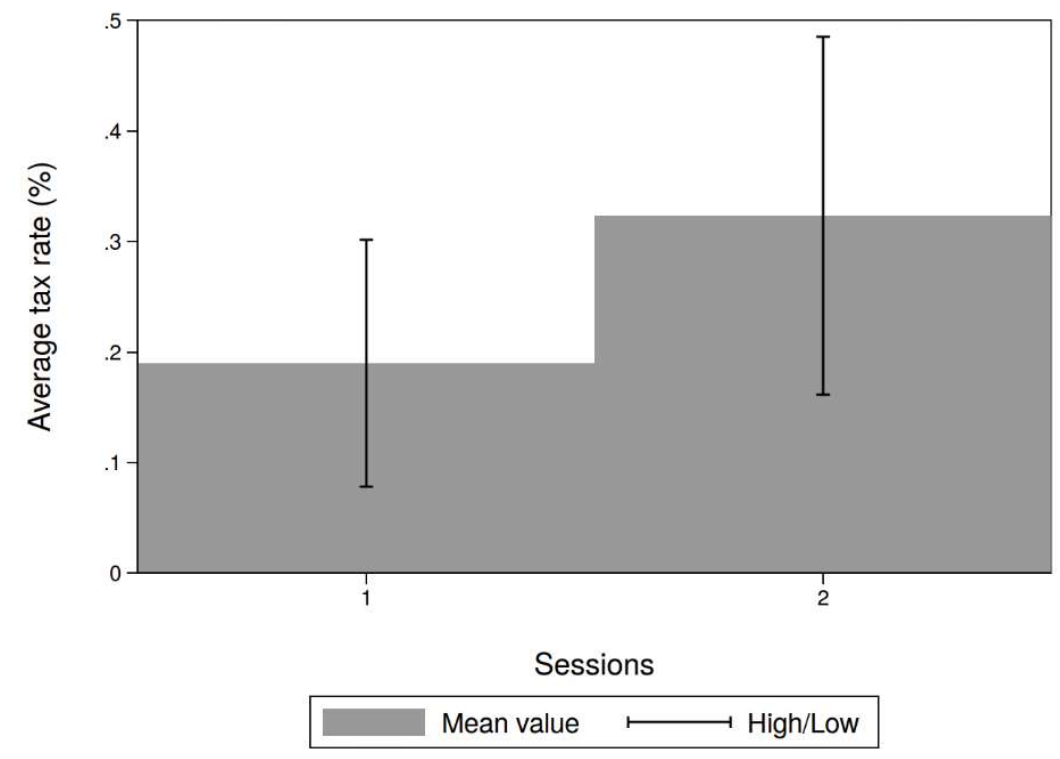

Note: Session 1 is certain effort reward; Session 2 is uncertain effort reward.

Figure 3. Average tax rate selected by high risk averse subjects

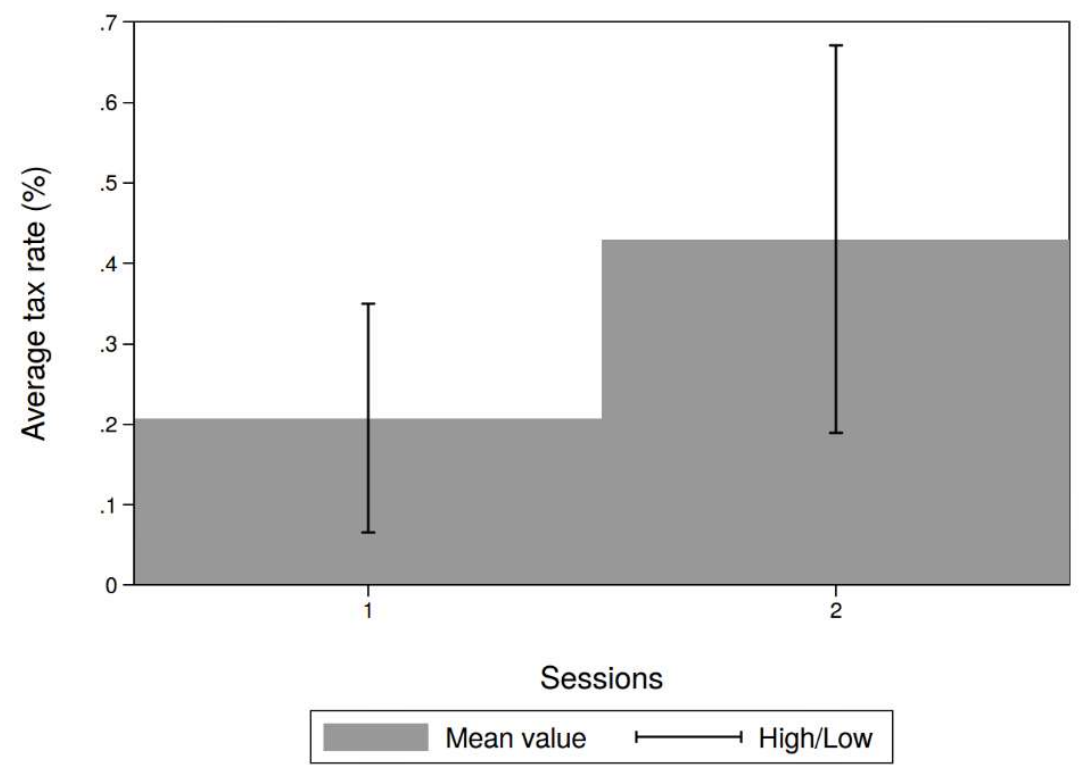

Note: Session 1 is certain effort reward; Session 2 is uncertain effort reward.

It is worth noticing, however, that the difference between Sessions 1 and 2 is not statistically significant according to the Mann-Whitney test $(\mathrm{p}=0.15)$. A possible explanation may be that the change in the level of risk between the two scenarios was not large enough to induce participants - and in particular those with a low degree of risk aversion - to react modifying remarkably their ideal tax rate. In order to test this hypothesis, we consider a reduced sample of high risk averse individuals, those who are expected to change their behavior most across risk treatments. In particular, we define a subsample of individuals that displayed a degree of risk 
aversion not lower than the median level computed on the whole sample, i.e., values of RISK_LOVE equal or lower than 10. As expected, when looking at this subsample only (Figure $3)$, the difference in the average $t^{*}$ between Sessions 1 and 2 is larger than before $\left(t^{*}\right.$ increases from $21 \%$ to $43 \%)$ and now it is also statistically significant $(p=0.05)$, thus confirming that high risk averse individuals prefer more redistribution when the uncertainty of their final payoff increases.

\subsubsection{Regression analysis}

In order to investigate more in depth the relationship between redistributive preferences and risk attitudes, we carried out a regression analysis estimating a Tobit model with the tax rate $t^{*}$ as the dependent variable. In particular, we adopted an incremental regression approach: we first consider a baseline model which includes among the covariates only the main variables of interest, without accounting for potential confounding factors; then, in order to test the robustness of our results, we progressively enriched the baseline model by accounting for some participants' characteristics that could somewhat interplay with risk-related variables in determining individual preferences for redistribution.

In the baseline specification (Model 1 in Table 3) we included: a dummy variable for the risk treatment (UNCERTAINTY), which is equal to 1 for Session 2 with uncertain effort reward; our measure of subjective risk attitudes (RISK_LOVE); the interaction between exogenous uncertainty and risk attitudes (UNCERTAINTY*RISK_LOVE); the individual effort choice, i.e., the number of correctly solved exercises to which an individual has committed in the effort task of the experiment (EFFORT).

In a first extension of this specification (Model 2) we added a set of controls for demographic characteristics $(F E M A L E=1$ for females; $A G E$, which is student's age; ITALIAN = 1 for Italian students). Then, we also accounted for the role of students' characteristics (Model 3: UNDER_GRADUATE $=1$ for undergraduate students; $E C O N \_D E P T=0 / 1$ for those subjects enrolled in a degree offered by the Department of Business/Economics; ECON_EXAMS, which is the number of courses in economics attended by the subject). Finally, we included a set of controls for their opinions and perceptions (Model 4), using participants' answers to the survey carried out at the end of the experiment. In particular, we focused on issues that have shown some predictive power in previous studies on preferences for redistribution (e.g., Checchi and Filippin 2004; Alesina and La Ferrara, 2005; Alesina and Giuliano, 2011; Beraldo et al., 2014) and considered the role played by the perceived social mobility $($ BETTER_FATHER $=1$ for 
subjects that believe to have better chances of earnings than their father) and by beliefs about the main source of income inequalities (SUCCESS_LUCK, which takes values from 1 to 5 according to the importance placed on luck as a determinant of economic success; POOR_TRAP, which takes values from 1 to 5 and measures the extent to which one believes that poor people are trapped in their condition because of their lack of effort in looking for a job). Table Al in the Appendix shows the summary statistics for all the variables used in the regression analysis.

Table 3. Tobit regression estimates. Dependent variable: selected tax rate $t^{*}$

\begin{tabular}{|c|c|c|c|c|}
\hline & Model 1 & Model 2 & Model 3 & Model 4 \\
\hline UNCERTAINTY & $\begin{array}{l}0.890 * * \\
(0.426)\end{array}$ & $\begin{array}{l}1.093 * * \\
(0.413)\end{array}$ & $\begin{array}{l}0.888 * * \\
(0.328)\end{array}$ & $\begin{array}{l}0.986^{* * *} \\
(0.341)\end{array}$ \\
\hline RISK_LOVE & $\begin{array}{c}0.010 \\
(0.022)\end{array}$ & $\begin{array}{c}0.019 \\
(0.019)\end{array}$ & $\begin{array}{l}-0.004 \\
(0.015)\end{array}$ & $\begin{array}{c}0.008 \\
(0.017)\end{array}$ \\
\hline UNCERTAINTY*RISK_LOVE & $\begin{array}{l}-0.069 * \\
(0.041)\end{array}$ & $\begin{array}{l}-0.089 * * \\
(0.039)\end{array}$ & $\begin{array}{c}-0.079 * * \\
(0.031)\end{array}$ & $\begin{array}{l}-0.088^{* * *} * \\
(0.031)\end{array}$ \\
\hline EFFORT & $\begin{array}{c}0.001 \\
(0.010)\end{array}$ & $\begin{array}{c}0.002 \\
(0.010)\end{array}$ & $\begin{array}{c}0.008 \\
(0.007)\end{array}$ & $\begin{array}{c}0.002 \\
(0.008)\end{array}$ \\
\hline FEMALE & - & $\begin{array}{l}-0.442^{* * *} \\
(0.161)\end{array}$ & $\begin{array}{l}-0.422^{* * *} \\
(0.127)\end{array}$ & $\begin{array}{l}-0.463^{* * *} \\
(0.119)\end{array}$ \\
\hline$A G E$ & - & $\begin{array}{c}0.034 \\
(0.035)\end{array}$ & $\begin{array}{l}-0.060 \\
(0.041)\end{array}$ & $\begin{array}{c}-0.051 \\
(0.035)\end{array}$ \\
\hline$I T A L I A N$ & - & $\begin{array}{l}-0.138 \\
(0.258)\end{array}$ & $\begin{array}{c}0.370 \\
(0.248)\end{array}$ & $\begin{array}{c}0.405^{*} \\
(0.224)\end{array}$ \\
\hline UNDER_GRADUATE & - & - & $\begin{array}{c}0.112 \\
(0.173)\end{array}$ & $\begin{array}{c}0.176 \\
(0.140)\end{array}$ \\
\hline$E C O N \_D E P T$ & - & - & $\begin{array}{l}-0.084 \\
(0.100)\end{array}$ & $\begin{array}{l}-0.109 \\
(0.079)\end{array}$ \\
\hline$E C O N \_E X A M S$ & - & - & $\begin{array}{l}0.114^{* * *} \\
(0.021)\end{array}$ & $\begin{array}{l}0.131^{* * *} \\
(0.027)\end{array}$ \\
\hline BETTER_FATHER & - & - & - & $\begin{array}{c}0.097 \\
(0.107)\end{array}$ \\
\hline SUCCESS_LUCK & - & - & - & $\begin{array}{l}0.180^{* *} \\
(0.080)\end{array}$ \\
\hline POORS_TRAP & - & - & - & $\begin{array}{l}-0.097 \\
(0.063)\end{array}$ \\
\hline Observations & 37 & 37 & 37 & 37 \\
\hline Prob $>\chi^{2}$ & 0.268 & 0.113 & 0.000 & 0.000 \\
\hline Pseudo $\mathrm{R}^{2}$ & 0.152 & 0.308 & 0.585 & 0.682 \\
\hline
\end{tabular}

$* p<0.10, * * p<0.05, * * * p<0.01$. Robust standard errors in parentheses. Combined skewness and kurtosis test for normality cannot reject the null hypothesis that $t^{*}$ and $R I S K \_L O V E$ are normally distributed (pvalue is 0.1370 and 0.2538 , respectively).

Results on the role of risk in shaping preferences for redistribution are consistent across all the specifications and confirms the evidence based on descriptive statistics discussed in the previous section. Moreover, the extension of the basic specification to include possible confounding 
effects progressively increases the goodness of fit of the statistical model, without basically altering the magnitude and the significance of coefficients of the main variables of interest. ${ }^{8}$ Therefore, we will refer to the most complete specification (Model 4) in commenting our estimates. Table 3 shows that introducing uncertainty in effort reward increases the preferred tax rate, conditionally to the degree of subjective risk attitudes: indeed, while first-order coefficient of UNCERTAINTY is positive, its interaction with RISK_LOVE is negative and the total effect remains positive until the value of RISK_LOVE is below or equal to 11, a threshold close to the sample median value used in the test of the difference in average $t^{*}$ between Sessions 1 and 2 for high risk averse individuals (Figure 3). This finding supports the view that high risk averse individuals are likely to prefer more redistribution when they have to take their decisions in more risky environments, while low risk averse and risk neutral individuals (i.e., those with values of RISK_LOVE between 12 and 16) and - a fortiori - the risk loving ones (.e., those with values of $R I S K \_L O V E$ higher than 16) are expected to prefer lower tax rates. Interestingly, the variable RISK_LOVE shows the expected negative relationship with $t^{*}$ and it is statistically significant only in the treatment with uncertainty effort reward, as highlighted by the interaction between RISK_LOVE and UNCERTAINTY; this result suggests that the individuals operating in very risky environments will ask for more redistribution when their risk aversion increases, in order to insure against the strong uncertainty in the final income distribution, while subjective risk attitudes do not play a significant role in shaping preferences for redistribution when individuals take their decisions in low risk environments. As for the effect of the individual effort (EFFORT), we do not uncover any clear relationship with the preferred tax rate, as its coefficient is very small and always statistically insignificant; hence, individual decisions on optimal effort and the desired redistribution appear to be here basically independent.

Looking now at the role of the other variables in the models, the presence of gender differences $(F E M A L E)$ is persistent across all specifications and confirms that women prefer lower levels of redistribution with respect to men. Notice that some previous studies support the opposite conclusion (e.g., Alesina and Giuliano, 2011; Durante et al., 2014), while other contributions (e.g., Checchi and Filippin, 2004; Beraldo et al., 2014) are consistent with our findings. A possible explanation for this discrepancy may be that American and European women have different attitudes toward redistribution, but further research is needed in order to understand

\footnotetext{
${ }^{8}$ Rather, the statistical significance of the coefficient of UNCERTANTY and of its interaction with RISK_LOVE increases in the most complete specification (Model 4).
} 
the heterogeneity of the results across studies. Another interesting finding (in Model 4) is that Italian born subjects $(I T A L I A N)$ ask for more redistribution than foreign born ones. This pattern may be due to the fact that the latter are all immigrants, hence they, or their parents, left the country of origin in order to better their economic position. Consequently, according to the POUM hypothesis, they may prefer a lower degree of redistribution, since they expect to increase their income over time and thus feel to be harmed by strongly redistributive taxation in the future. A second argument that can be used to interpret this result is that inequalities are more severe in their country of origin than in Italy, hence they may consider already enough egalitarian a society that Italian born people may consider unequal. As for students' characteristics, when we test the impact of the field of studies, we can notice that the dummy denoting subjects who are enrolled in a degree offered by the Department of Economics $\left(E C O N \_D E P T\right)$ is not significant, while if we look at the actual number of economics courses attended by the subject $\left(E C O N \_E X A M S\right)$, the variable shows a positive and highly significant coefficient. ${ }^{9}$ This is possibly due to the fact that economics courses emphasize redistributive issues better than business ones. Finally, as for the role of cultural background, individual beliefs about the source of income inequalities seem to affect preferences for redistribution, confirming previous evidence in the literature (e.g., Alesina and Glaeser, 2004; Alesina and Angeletos, 2005; Krawczyk, 2010). In particular, the variable SUCCESS_LUCK shows a significant and positive coefficient, thus suggesting that subjects that place more importance on luck as a determinant of economic success rely more on redistributive policies and decide to select higher tax rates, further strengthening the interpretation of redistribution as an insurance mechanism.

Overall, these results confirm the simple test of differences in average $t^{*}$ across treatments, controlling for several determinants of preferences for redistribution. To conclude, it is worth comparing our findings with those obtained in Durante et al. (2014), which is the only recent experimental study that accounted for the role of risk in determining preferences for redistribution, although in their paper this issue was only one of the many controls included in the analysis, focused on social concerns related to income inequality. Results from our experiment are not only consistent with, but also improve those of Durante et al. (2014). First, the evidence of a positive relationship between exogenous risk faced by individuals and preferences for redistribution proved to be robust to the adoption of a between-subject approach, thus suggesting that their findings were not driven by the specific within-subject design adopted,

\footnotetext{
${ }^{9}$ A similar result can be found in Durante et al. (2014).
} 
which suffers from the well-known problems of carry-over and experimenter demand effects (e.g., Zizzo, 2009; Charness et al., 2012). More in detail, in their experiment Durante et al. (2014) asked the same subjects to state their desired level of redistribution depending on different initial distributions of their income, which could be ordered in terms of associated risk. However, as the authors point out, these different distributions were defined according to rules that could be ordered using their moral worthiness. Therefore, more risky distributional rules could have led to a higher degree of redistribution simply because they were perceived as rewarding unworthy people. In other words, participants may have adopted a moral criterion in choosing the tax rate, instead of considering an insurance mechanism for risk. Our results exclude this moral interpretation, since in a between-subject design only one distributional rule (i.e., a low-risk or a high-risk scenario, depending on the certainty of effort reward) is presented to each participant, who has no information on the features of the other session. Second, as for the role of subjective risk attitudes in driving the preferences for redistribution, while we find here a systematic negative correlation between RISK_LOVE and $t^{*}$ for subjects facing an uncertain reward effort, in the study of Durante et al. (2014) the associated coefficient was often not statistically significant and contradictory in terms of sign. A possible explanation of the difference is likely to be due to the less refined measure of risk attitudes - based on 1-5 scale instead of the 1-20 one used here - rather than to a real weakness of the relationship of interest.

\section{Conclusions}

In this study we exploit a between-subject laboratory experiment to investigate the existence of a relationship between risk attitudes and preferences for redistribution. Our evidence suggests that when subjects face more uncertainty about the outcome of their effort (hence, their future position in the income distribution) they vote for a higher tax rate, and this demand for redistribution increases with the subjective degree of risk aversion. Our interpretation is that individuals look at taxation as to a form of insurance against uncertainty.

Our results certainly are limited by the small size of our sample, and by the considerations of students with a specific background only. Hence, further investigations are needed to support the view of risk-averse people using taxes as an insurance mechanism in a risky business environment. However, one also needs to recognize that the outcome of redistributive policies, but also social mobility, need time to materialize. The passing of time increases risk on the one hand, but also makes time preferences a likely important factor to shape preferences for redistribution. As risk and time preferences are intrinsically connected (e.g., Andreoni and 
Sprenger, 2012), time can then be a confounding factor if we are interested in the role of risk, and vice versa. Notice that our experimental design allowed us to control for this problem, as the final income distribution was generated immediately and all monetary rewards were paid soon at the end of the session, thus eliminating any sort of late reward bias when analyzing the effect of risk attitudes. Nevertheless, the role of time as different from risk preferences in shaping preferences for redistribution represents an important issue to be investigated in a future test. 


\section{References}

Abdellaoui, M, Driouchi, A. and l'Haridon O. (2011). Risk aversion elicitation: reconciling tractability and bias minimization. Theory and Decision, 71(1), pp. 63-80.

Alesina, A. and Angeletos, G.M. (2005). Fairness and Redistribution: US vs. Europe. American Economic Review, 95, 913-35.

Alesina, A. and Giuliano P. (2011). Preferences for redistribution. In Benhabib J., M. Jackson, A. Bisin (eds.), Handbook of Social Economics, vol. 1A, North Holland, pp. 93-131.

Alesina, A. and Glaeser, E. (2004), Fighting Poverty in the US and Europe: A World of Difference, Oxford University Press.

Alesina, A. and La Ferrara, E. (2005). Preferences for Redistribution in the Land of Opportunities. Journal of Public Economics, 89: 897-931.

Alm, J. and Jacobson, S. (2007). Using laboratory experiments in public economics. National Tax Journal, pp. 129-152.

Andreoni, J. and Sprenger, C. (2012). Risk preferences are not time preferences. American Economic Review, 102(7), pp. 3357-3376.

Beck, J. H. (1994). An experimental test of preferences for the distribution of income and individual risk aversion. Eastern Economic Journal, pp. 131-145.

Beckman, S.R., Formby, J.P. and Smith, W.J. (2004). Efficiency, Equity and Democracy: Experimental Evidence on Okun's Leaky Bucket. In Cowell F. (ed.), Inequality, Welfare and Income Distribution: Experimental Approaches (Research on Economic Inequality, Vol. 11), Emerald Group Publishing, pp. 17-42.

Benabou, R. and Ok, E.A. (2001). Social mobility and the demand for redistribution: The POUM hypothesis. Quarterly Journal of Economics, 116(2), pp. 447-487.

Beraldo, S., Piacenza, M., and Turati, G. (2014). Must reward hard work? An experiment on personal responsibility and preferences for redistribution. CSEF Working Paper Series, No. 377 , University of Naples, Italy.

Buch, C. M. and Engel, C. (2012). The tradeoff between redistribution and effort: Evidence from the field and from the lab. CESifo Working Paper Series, No. 3808, Munich, Germany.

Camerer, C.F. and Hogarth, R.M. (1999). The effects of financial incentives in experiments: A review and capital-labor-production framework. Journal of Risk and Uncertainty, 19(1-3). pp. 742.

Charness, G., Gneezy, U. and Kuhn, M.A. (2012). Experimental methods: Between-subject and within-subject design. Journal of Economic Behavior \& Organization, 81, pp. 1-8. 
Checchi, D. and Filippin, A. (2004). An experimental study of the POUM hypothesis. In Cowell F. (ed.), Inequality, Welfare and Income Distribution: Experimental Approaches, Research on Economic Inequality, vol. 11, Emerald Group Publishing Limited, pp. 115-136.

Crosetto, P. and Filippin, A. (2013). The Bomb risk elicitation task. Journal of Risk and Uncertainty, 47(1), pp. 31-65.

Crosetto, P. and Filippin, A. (2016). A theoretical and experimental appraisal of four risk elicitation methods. Experimental Economics, 19(3), pp. 613-641.

Croson, R. and Gneezy, U. (2009). Gender differences in preferences. Journal of Economic Literature, $47(2), 448-474$.

Dohmen, T., Falk, A., Huffman, D., and Sunde, U. (2010). Are risk aversion and impatience related to cognitive ability? American Economic Review, 100, pp. 1238-1260.

Durante, R., Putterman, L., and Weele, J. (2014). Preferences for redistribution and perception of fairness: An experimental study. Journal of the European Economic Association, 12(4), pp. 1059-1086.

Gärtner, M., Mollerstrom, J., and Seim, D. (2017). Individual risk preferences and the demand for redistribution. Journal of Public Economics, 153, pp. 49-55.

Krawczyk, M. (2010). A Glimpse Through the Veil of Ignorance: Equality of Opportunity and Support for Redistribution. Journal of Public Economics, 94, pp. 131-141.

Rawls, J. (1971). A Theory of Justice. Harvard University.

Smith V. and Walker J. (1993). Monetary rewards and decision cost in experimental economics. Economic Inquiry, 1993, 31 (2), pp. 245-261.

Zizzo, D.J. (2010). Experimenter demand effects in economic experiments. Experimental Economics, 13(1), pp 75-98. 


\section{APPENDIX}

Experiment instructions, answer sheets and questionnaire ${ }^{10}$

\section{INSTRUCTIONS}

\section{Privacy statement}

We ensure that your personal data will be collected anonymously and in accordance with the Italian law. Details are reported in the next paragraphs.

As far as your personal data are concerned, we inform you that

- personal data will be treated in anonymous form and the answer sheets will have the same treatment

- the person in charge of the collection and the treatment of your data is Matteo Assandri

- data will be collected for scientific purposes only and they will not be communicated to third parties

According to art. 7 D.L. 196/2013 in the Italian law, the subject has the right to know the collected data, to intervene in the treatment of those data asking whether some data exist, their origin, the rationale and the scope of the data collection. Subjects can obtain anonymization or deletion if data are treated against the law. He/She can also contest, for legitimate reasons, the treatment of his/her personal data, even if they are in accordance with the purposes of the collection.

\section{GENERAL INSTRUCTIONS}

First of all we welcome the participants and we thank them for their participation.

The experiment you are about to be part of aims at understanding individual preferences formation in economic contexts and is part of a research projects of the University of Torino, founded by the Laboratorio di Economia Sperimentale, Cognitiva e Computazionale, University of Piemonte Orientale.

\footnotetext{
${ }^{10}$ Instructions refer to Session 1. Participants faced an Italian language version of the below instructions.
} 


\section{Preliminary information}

The experiment will be divided in three parts $(A, B, C)$. In the first two you will have to take decisions in accordance with your preferences. Both decisions will be remunerated at the end of the experiment in ways that will be later described. The third part will be a demographic survey. Part A will deal with attitudes towards risk, Part B will deal with social preferences. During Part B you will be asked to solve several exercises, hence you will have some time to practice.

The privacy statement has been read out loud by the experimenter as well as the those preliminary instructions. Each Part's instructions will be read out loud as well. Then, you will have some time to ask questions and to make you choices. Once you had completed your choices, you have to put your pen on the table and wait silently for others subjects to finish.

Please, check that you have all the following material on your desk.

- "Instructions"

- "Answers"

- A small sheet titled "ANSWER COPY"

- A small signed sheet with the number we assigned you

As previously stated, you will be remunerated for participating to this experiments. You will be provided with an endowment in the form of tokens. During the experiments you will have the opportunity to take decisions that will allow you to change the amount of your endowment.

At the end of the experiment, you will be able to convert tokens into Euros at the following rates:

- 1 token $=0.01 €$ in part $\mathrm{A}$

- 1 token $=0.03 €$ in part B.2

\section{General instructions}

The following instructions have to be followed in each Part:

- Please, remain silent while answering the questions. If you have doubts raise your hand and the experimenter will help you.

- Fill the answers in the appropriate space.

- Be careful when answering. 
- Be sincere.

- Once you answered all the question in the Part, wait for further instructions before starting the next one.

- There are no right or wrong answers. You have to answer according to your preferences.

- Some choices will be determined by random extractions from an urn at the end of the session. At the end of the extractions, you can check the content of the urn.

We thank everyone for the participation and we wish you good luck.

\section{INSTRUCTIONS: PART A}

In this part you will have to take decisions under uncertainty.

Please, be careful while answering and do it silently. If you have questions, raise your hand.

\section{Instructions}

Among the answer sheets, pick the one named "PART A".

As you can see, in each row of the table you have the opportunity to choose between two alternatives, Column A and Column B, circling your choice in the last column from the first to the last row.

As you can see:

- Column A presents sure amounts. Each row presents an increasing amount.

- Column B presents an all-or-nothing lottery. You can either win 150 tokens with 50\% probability or 0 tokens with $50 \%$ probability. Such lottery does not change from one row to the next.

At the end of the experiment, one of the rows will be randomly selected and you will be remunerated according to your choice. If you chose the lottery, you will have to play it. 
Example

\begin{tabular}{|c|c|c|c|}
\hline Row & Column A & Column B & Choice \\
\hline 1 & 0 token & $50 \% 20$ tokens $50 \% 0$ tokens & A $\underline{\mathbf{B}}$ \\
\hline 2 & 2 token & $50 \% 20$ tokens $50 \% 0$ tokens & A $\underline{\mathbf{B}}$ \\
\hline 3 & 4 token & $50 \% 20$ tokens $50 \% 0$ tokens & A $\underline{\mathbf{B}}$ \\
\hline 4 & 6 token & $50 \% 20$ tokens $50 \% 0$ tokens & A $\underline{\mathbf{B}}$ \\
\hline 5 & 8 token & $50 \% 20$ tokens $50 \% 0$ tokens & A $\underline{\mathbf{B}}$ \\
\hline 6 & 10 token & $50 \% 20$ tokens $50 \% 0$ tokens & A $\underline{\mathbf{B}}$ \\
\hline 7 & 12 token & $50 \% 20$ tokens $50 \% 0$ tokens & $\underline{\mathbf{A}}$ B \\
\hline 8 & 14 token & $50 \% 20$ tokens $50 \% 0$ tokens & $\underline{\mathbf{A}}$ B \\
\hline 9 & 16 token & $50 \% 20$ tokens $50 \% 0$ tokens & $\underline{\mathbf{A}}$ B \\
\hline 10 & 18 token & $50 \% 20$ tokens $50 \% 0$ tokens & $\underline{\mathbf{A}}$ B \\
\hline
\end{tabular}

Suppose that, at the end of the experiment, row 7 is the outcome of the random draw from an urn with numbers from 1 to 10. If in that row your choice was A, you will receive the amount of Euro corresponding to 12 Tokens. On the other hand, if the choice was B, you will have to play the lottery. At the end of the experiment you will have to throw a dice: if the outcome is 1,2 or 3 you will win 0 tokens; if the outcome is 4,5 or 6 , you will win 20 tokens.

You can now fill Part A. Use the sheet titled Part A among Answers.

\section{INSTRUCTIONS: PART B.1}

In this part you will have to take economic decisions. Each decision is allowed. You will have to decide according to your preferences only. Please, be careful while answering and be silent. If you have questions, raise your hand.

- You will face 4x4 tables. In each cell there will be a decimal number.

- You will have to find couples of numbers that add up to 10. The number of couples will be the solution and will have to be written in the appropriate row.

- Each table contains at least one and at most four couples. 


\section{Example}

\begin{tabular}{|l|l|l|l|}
\hline 2.15 & 4.19 & 3.22 & 6.01 \\
\hline 8.02 & $\mathbf{6 . 7 8}$ & 1.08 & 4.05 \\
\hline 1.01 & 7.54 & 4.93 & 9.99 \\
\hline 2.02 & 5.68 & 4.33 & 1.69 \\
\hline
\end{tabular}

Solution: 1

As you can see, $6.78+3.22=10$

You have 10 minutes in order to solve correctly as much exercises as you can among those presented in the page titled "Training exercises" among the Answer sheets. At the end of that time, the correct answers will be presented to you and you will be able to self-assess your performance. Then, we will move to the next Part.

You can start now.

\section{INSTRUCTIONS: PART B.2}

\section{Instructions}

This Part will develop as follows.

1. Each one of you was provided with the same initial income. Such amount of tokens can be seen in the first row of section B.2 in the Answers.

2. Each one of you has the possibility to increase such amount. In order to do it, you will have to solve exercises as the ones presented in Part B.1. You will have to choose a number of exercises between 0 and 25. Each one will allow you to increase your income. Consider carefully the amount of exercises you think you are able to solve.

3. Each exercise you will commit to solve will add 2 tokens to your income, but you will not be allowed to leave the room until you solved correctly the number of exercises you committed to. You will have to report the number of exercises you chose both by circling the value in the appropriate table, both by writing it the number in the "Answer copy" sheet.

4. The final income, i.e. the sum of the initial one and the one obtained with exercises, will be taxed. Fiscal revenues will be equally divided among participants. 
Each one of you has to select the proportional tax rate you would like to apply in case you would be completely free to decide for the whole society. Such rate has to be chosen among those in the appropriate table in the Answer sheets.

As before, you will have to circle your choice in the table and write the number in the "Answer copy" sheet.

Once you chose the tax rate, you will have to correctly solve the number of exercises you committed to. Those exercises are in the "Exercises" page in the Answer sheets.

NOTICE: if you committed to solve one exercise, you will have to solve the first. If you chose two, the first and the second and so on.

Once you solved all the exercises you committed to, raise your hand and the experimenter will check your answers.

5. At the end of the experiment a tax rate will be randomly selected among those proposed by subjects by means of an extraction from an urn. Using that tax rate, we will compute the amount of taxes due from each one of you and the transfers.

6. Once we will have calculated the amount of token each of you earned, they will be converted in Euro.

Example: suppose there are only two participants with final income 10 and 20 tokens respectively. Suppose that the random draw determined that the tax rate was $50 \%$.

Taxes due by $A$ will be 5 , taxes due by $B$ will be 10 . Hence the fiscal revenues will be 15 and each subject will receive 7.5 in transfer.

Subject A will convert an income of 10-5+7.5=12.5 token; similarly, B will convert 20$10+7.5=17.5$ token.

You can now start.

Once you copied your answers in the "Answer Copy" sheet, raise your hand and the experimenter will collect that sheet. Then you can start solving the exercises.

\section{INSTRUCTIONS: PART C}

This part consists in filling the survey you find in the Answers. Now you can start. 


\section{FINAL INSTRUCTIONS}

Now we will determine the random elements according to the aforementioned rules.

Those elements will be:

- Tax rate

- Part A's row that will be paid and eventual lottery

Then, you will have to hand in all the material we provided and come to the experimenter desk for receiving the payment The only thing you have to keep with you is the signed sheet with your number. 


\section{ANSWERS}

\section{Part A}

You have to decide if you prefer option A or option B in each row. Remember: Column A offers a sure amount of tokens, while Column B is a lottery that allows you to win 150 tokens with probability $50 \%$ and 0 tokens with probability $50 \%$.

\begin{tabular}{|c|c|c|c|}
\hline Row & Column A & Column B & Choice \\
\hline 1 & 0 token & $50 \% 150$ tokens $50 \% 0$ tokens & A B \\
\hline 2 & 5 token & $50 \% 150$ tokens $50 \% 0$ tokens & A B \\
\hline 3 & 10 token & $50 \% 150$ tokens $50 \% 0$ tokens & A B \\
\hline 4 & 15 token & $50 \% 150$ tokens $50 \% 0$ tokens & A B \\
\hline 5 & 20 token & $50 \% 150$ tokens $50 \% 0$ tokens & A B \\
\hline 6 & 25 token & $50 \% 150$ tokens $50 \% 0$ tokens & A B \\
\hline 7 & 30 token & $50 \% 150$ tokens $50 \% 0$ tokens & A B \\
\hline 8 & 35 token & $50 \% 150$ tokens $50 \% 0$ tokens & A B \\
\hline 9 & 40 token & $50 \% 150$ tokens $50 \% 0$ tokens & A B \\
\hline 10 & 45 token & $50 \% 150$ tokens $50 \% 0$ tokens & A B \\
\hline 11 & 50 token & $50 \% 150$ tokens $50 \% 0$ tokens & A B \\
\hline 12 & 55 token & $50 \% 150$ tokens $50 \% 0$ tokens & A B \\
\hline 13 & 60 token & $50 \% 150$ tokens $50 \% 0$ tokens & A B \\
\hline 14 & 65 token & $50 \% 150$ tokens $50 \% 0$ tokens & A B \\
\hline 15 & 70 token & $50 \% 150$ tokens $50 \% 0$ tokens & A B \\
\hline 16 & 75 token & $50 \% 150$ tokens $50 \% 0$ tokens & A B \\
\hline 17 & 80 token & $50 \% 150$ tokens $50 \% 0$ tokens & A B \\
\hline 18 & 90 token & $50 \% 150$ tokens $50 \% 0$ tokens & A B \\
\hline 20 & 95 token & $50 \% 150$ tokens $50 \% 0$ tokens & A B \\
\hline
\end{tabular}




\section{Part B.1}

TRAINING EXERCISES

Results

\begin{tabular}{|l|l|l|l|l|l|l|l|l|l|}
\hline 1 & 2 & 3 & 4 & 5 & 6 & 7 & 8 & 9 & 10 \\
\hline & & & & & & & & & \\
\hline
\end{tabular}

\begin{tabular}{|l|l|l|l|}
\hline 8.01 & 9.72 & 2.38 & 1.62 \\
\hline 3.40 & 8.38 & 4.81 & 7.47 \\
\hline 3.93 & 1.82 & 5.78 & 6.50 \\
\hline 5.78 & 8.37 & 1.95 & 3.88 \\
\hline
\end{tabular}

$\mathbf{6}$\begin{tabular}{|l|l|l|l|}
\hline 6.26 & 8.92 & 6.55 & 9.84 \\
\hline 1.97 & 3.27 & 3.61 & 2.09 \\
\hline 4.66 & 9.16 & 8.42 & 7.57 \\
\hline 4.09 & 7.91 & 3.39 & 5.34 \\
\hline
\end{tabular}

$\mathbf{2}$\begin{tabular}{|l|l|l|l|}
\hline 8.36 & 8.34 & 8.48 & 1.75 \\
\hline 5.08 & 8.43 & 8.23 & 1.64 \\
\hline 9.76 & 2.56 & 4.52 & 2.20 \\
\hline 4.89 & 6.84 & 1.77 & 8.20 \\
\hline
\end{tabular}

7 \begin{tabular}{|l|l|l|l|}
\hline 5.09 & 7.61 & 3.42 & 7.98 \\
\hline 7.24 & 6.58 & 0.31 & 4.24 \\
\hline 4.48 & 2.74 & 2.52 & 7.58 \\
\hline 7.26 & 7.48 & 4.87 & 9.69 \\
\hline
\end{tabular}

$\mathbf{3}$\begin{tabular}{|l|l|l|l|}
\hline 7.56 & 1.57 & 2.6 & 1.47 \\
\cline { 2 - 5 } 9.38 & 8.05 & 8.74 & 7.64 \\
\hline 1.95 & 9.86 & 8.07 & 5.62 \\
\hline 2.28 & 9.41 & 2.50 & 8.73 \\
\hline
\end{tabular}

\begin{tabular}{|l|l|l|l|}
\hline 5.63 & 8.76 & 6.29 & 7.74 \\
\hline 4.95 & 2.39 & 8.43 & 9.91 \\
\hline 7.04 & 8.11 & 4.66 & 2.96 \\
\hline 8.96 & 3.87 & 2.80 & 8.50 \\
\hline
\end{tabular}

4 \begin{tabular}{|c|c|c|c|}
\hline 6.72 & 2.56 & 5.00 & 7.04 \\
\hline 7.44 & 9.56 & 2.09 & 8.80 \\
\hline 4.77 & 1.54 & 5.55 & 6.78 \\
\hline 2.96 & 6.68 & 4.20 & 7.91 \\
\hline
\end{tabular}

$\mathbf{9}$\begin{tabular}{|l|l|l|l|}
\hline 8.96 & 8.90 & 7.48 & 6.24 \\
\hline 1.85 & 4.59 & 1.43 & 1.04 \\
\hline 1.42 & 2.76 & 3.73 & 8.15 \\
\hline 1.49 & 7.50 & 9.37 & 0.63 \\
\hline
\end{tabular}

5 \begin{tabular}{|l|l|l|l|}
\hline 4.36 & 9.20 & 8.32 & 6.65 \\
\hline 6.61 & 8.21 & 6.99 & 4.45 \\
\hline 1.19 & 3.01 & 3.39 & 0.68 \\
\hline 7.71 & 4.45 & 9.32 & 1.79 \\
\hline
\end{tabular}

\begin{tabular}{|c|c|c|c|c|}
\hline 9.40 & 5.09 & 6.39 & 0.60 \\
\hline 3.22 & 8.06 & 7.00 & 4.66 \\
\hline 10.02 & 5.34 & 8.35 & 2.34 \\
\hline 3.00 & 8.95 & 9.22 & 1.65 \\
\hline
\end{tabular}




\section{Part B.2}

Your values are the following:

- Your initial income is 100 tokens

- Other participants' income is the same as yours, i.e. 100 tokens.

How many exercises you want to commit to solve (from 0 to 25)? Here we reported the amount of income you can earn for each choice: circle the option you prefer and report the number on the "Answer Copy".

\begin{tabular}{|l|c|c|c|c|c|c|c|c|c|c|c|c|c|}
\hline Exercises & 1 & 2 & 3 & 4 & 5 & 6 & 7 & 8 & 9 & 10 & 11 & 12 & 13 \\
\hline Tokens & 2 & 4 & 6 & 8 & 10 & 12 & 14 & 16 & 18 & 20 & 22 & 24 & 26 \\
\hline
\end{tabular}

\begin{tabular}{|l|l|l|l|l|l|l|l|l|l|l|l|l|}
\hline Exercises & 14 & 15 & 16 & 17 & 18 & 19 & 20 & 21 & 22 & 23 & 24 & 25 \\
\hline Tokens & 28 & 30 & 32 & 34 & 36 & 38 & 40 & 42 & 44 & 46 & 48 & 50 \\
\hline
\end{tabular}

What is the tax rate you would like to implement? Circle the answer and report the number in the "Answer Copy".

\begin{tabular}{|l|l|l|l|l|l|l|l|l|l|l|}
\hline $0 \%$ & $10 \%$ & $20 \%$ & $30 \%$ & $40 \%$ & $50 \%$ & $60 \%$ & $70 \%$ & $80 \%$ & $90 \%$ & $100 \%$ \\
\hline
\end{tabular}


EXERCISES

Results

\begin{tabular}{|l|l|l|l|l|l|l|l|l|l|l|l|l|l|}
\hline 1 & 2 & 3 & 4 & 5 & 6 & 7 & 8 & 9 & 10 & 11 & 12 & 13 & 14 \\
\hline & & & & & & & & & & & & & \\
\hline
\end{tabular}

$\mathbf{1} 1$\begin{tabular}{|l|l|l|l|}
\hline 4.51 & 4.93 & 4.61 & 9.48 \\
\hline 6.90 & 4.63 & 3.10 & 4.66 \\
\hline 2.01 & 4.97 & 3.70 & 8.50 \\
\hline 5.03 & 5.07 & 4.99 & 0.52 \\
\hline
\end{tabular}

2 \begin{tabular}{|l|l|l|l|}
\hline 4.23 & 6.27 & 7.79 & 3.98 \\
\hline 1.18 & 7.63 & 2.35 & 4.13 \\
\hline 5.87 & 4.55 & 4.98 & 7.19 \\
\hline 4.98 & 7.34 & 3.19 & 7.15 \\
\hline
\end{tabular}

3 \begin{tabular}{|l|l|l|l|}
\hline 6.84 & 2.65 & 5.06 & 7.59 \\
\hline 3.67 & 6.89 & 4.18 & 6.83 \\
\hline 6.63 & 5.82 & 7.18 & 3.11 \\
\hline 4.32 & 2.70 & 7.70 & 5.92 \\
\hline
\end{tabular}

\begin{tabular}{|l|l|l|l|}
\hline 5.18 & 5.57 & 5.92 & 4.43 \\
\hline 4.40 & 9.67 & 3.14 & 9.36 \\
\hline 46.62 & 4.82 & 5.40 & 6.21 \\
\hline 3.08 & 7.57 & 5.13 & 5.69 \\
\hline
\end{tabular}

$\mathbf{5}$\begin{tabular}{|l|l|l|l|}
\hline 4.26 & 6.38 & 5.74 & 8.09 \\
\hline 3.58 & 7.75 & 2.25 & 9.07 \\
\hline 8.96 & 7.56 & 1.91 & 9.49 \\
\hline 5.28 & 5.94 & 4.72 & 8.21 \\
\hline
\end{tabular}

\begin{tabular}{|l|l|l|l|}
\hline 4.52 & 1.49 & 3.22 & 2.05 \\
\cline { 2 - 5 } 8.08 & 4.51 & 8.33 & 5.49 \\
\cline { 2 - 5 } 8.51 & 2.75 & 7.25 & 7.07 \\
\hline 4.95 & 5.48 & 4.94 & 3.92 \\
\hline
\end{tabular}

9 \begin{tabular}{|l|l|l|l|}
\hline 3.13 & 6.47 & 7.15 & 6.72 \\
\cline { 2 - 5 } 9.51 & 8.18 & 7.38 & 7.11 \\
\hline 6.19 & 1.82 & 2.07 & 6.80 \\
\hline 2.88 & 6.83 & 5.05 & 5.13 \\
\hline
\end{tabular}

\begin{tabular}{|l|l|l|l|l|}
\hline 5.73 & 4.59 & 3.93 & 2.47 \\
\hline 10 & 2.08 & 1.33 & 7.42 & 8.41 \\
\hline 5.92 & 7.74 & 7.53 & 9.05 \\
\hline 6.99 & 2.58 & 1.59 & 8.28 \\
\hline
\end{tabular}

\begin{tabular}{|l|l|l|l|}
\hline 7.26 & 4.59 & 6.66 & 0.94 \\
\hline 5.59 & 1.89 & 1.91 & 2.74 \\
\hline 1.40 & 9.06 & 4.89 & 4.52 \\
\hline 1.49 & 9.16 & 5.51 & 5.41 \\
\hline \multicolumn{2}{|c|}{1.40}
\end{tabular}

12 \begin{tabular}{|l|l|l|l|}
\hline 3.31 & 1.09 & 7.25 & 2.78 \\
\hline 5.51 & 3.51 & 7.86 & 4.49 \\
\hline 6.41 & 4.88 & 5.79 & 2.14 \\
\hline 2.15 & 7.85 & 3.59 & 7.05 \\
\hline
\end{tabular}

\begin{tabular}{|c|c|c|c|}
\hline 6.68 & 4.15 & 7.66 & 2.77 \\
\hline 8.48 & 3.26 & 6.54 & 9.25 \\
\hline 5.26 & 6.27 & 4.16 & 9.36 \\
\hline 2.34 & 5.95 & 3.57 & 3.32 \\
\hline
\end{tabular}

7 \begin{tabular}{|l|l|l|l|}
\hline 7.09 & 8.84 & 1.95 & 1.96 \\
\hline 7.15 & 4.19 & 9.86 & 2.85 \\
\hline 9.51 & 8.97 & 5.81 & 4.70 \\
\hline 6.55 & 9.46 & 8.05 & 1.16 \\
\hline
\end{tabular}

\begin{tabular}{c|c|c|c|c|}
\hline \multirow{4}{*}{14} & 1.22 & 2.12 & 7.68 & 4.24 \\
\cline { 2 - 5 } & 7.82 & 4.16 & 5.84 & 3.65 \\
\cline { 2 - 5 } 4.80 & 1.16 & 7.17 & 6.02 \\
\cline { 2 - 5 } 8.84 & 4.86 & 2.18 & 4.82 \\
\hline
\end{tabular}


Results

\begin{tabular}{|l|l|l|l|l|l|l|l|l|l|l|}
\hline 15 & 16 & 17 & 18 & 19 & 20 & 21 & 22 & 23 & 24 & 25 \\
\hline & & & & & & & & & & \\
\hline
\end{tabular}

$\mathbf{1 5}$\begin{tabular}{|l|l|l|l|}
\hline 9.17 & 1.88 & 3.60 & 2.96 \\
\hline 3.86 & 2.29 & 7.90 & 2.10 \\
\hline 1.04 & 6.03 & 6.40 & 6.14 \\
\hline 7.04 & 8.77 & 1.97 & 5.65 \\
\hline
\end{tabular}

$\mathbf{2 2}$\begin{tabular}{|l|l|l|l|}
\hline 2.70 & 2.42 & 7.08 & 2.25 \\
\hline 6.29 & 7.00 & 6.28 & 1.38 \\
\hline 7.76 & 9.76 & 7.58 & 2.24 \\
\hline 8.53 & 9.67 & 5.04 & 1.47 \\
\hline
\end{tabular}

\begin{tabular}{|c|c|c|c|}
\hline 1.38 & 4.12 & 9.74 & 1.09 \\
\hline 16.59 & 9.97 & 2.52 & 7.48 \\
\hline 8.05 & 9.30 & 5.81 & 4.19 \\
\hline 7.53 & 7.94 & 7.24 & 0.03 \\
\hline
\end{tabular}

\begin{tabular}{|l|l|l|l|}
\hline 3.06 & 9.22 & 3.80 & 4.98 \\
\hline 2.43 & 4.24 & 5.76 & 1.75 \\
\hline 9.97 & 2.37 & 5.85 & 5.05 \\
\hline 6.20 & 7.73 & 1.70 & 7.20 \\
\hline
\end{tabular}

17 \begin{tabular}{|l|l|l|l|}
\hline 9.50 & 2.66 & 5.62 & 9.12 \\
\hline 6.22 & 3.16 & 1.18 & 1.45 \\
\hline 4.62 & 4.16 & 8.82 & 3.16 \\
\hline 2.11 & 4.76 & 3.78 & 1.68 \\
\hline
\end{tabular}

\begin{tabular}{|l|l|l|l|l|}
\hline 3.71 & 7.00 & 5.93 & 7.31 \\
\hline \multirow{2}{*}{24} & 5.85 & 7.00 & 9.85 & 2.15 \\
\cline { 2 - 5 } & 9.28 & 7.28 & 0.72 & 9.48 \\
\hline 2.60 & 0.44 & 4.76 & 9.56 \\
\hline
\end{tabular}

\begin{tabular}{|c|c|c|c|c|}
\hline 5.85 & 7.12 & 2.73 & 5.41 \\
\hline 18 & 5.97 & 6.67 & 1.38 & 1.45 \\
\cline { 2 - 5 } & 4.26 & 2.11 & 2.32 & 3.54 \\
\hline 2.88 & 2.85 & 6.72 & 2.70 \\
\hline
\end{tabular}

\begin{tabular}{|l|l|l|l|}
\hline 6.56 & 1.99 & 9.14 & 7.70 \\
\hline 6.19 & 2.78 & 5.45 & 7.29 \\
\hline 1.27 & 4.55 & 8.01 & 6.49 \\
\hline 8.25 & 8.73 & 5.50 & 5.32 \\
\hline
\end{tabular}

19 \begin{tabular}{|l|l|l|l|}
\hline 3.71 & 3.07 & 2.87 & 0.55 \\
\hline 2.75 & 5.24 & 2.54 & 9.31 \\
\hline 4.92 & 4.16 & 5.84 & 9.45 \\
\hline 3.03 & 3.80 & 8.60 & 3.05 \\
\hline
\end{tabular}

\begin{tabular}{|l|l|l|l|l|}
\hline 4.14 & 8.14 & 4.87 & 3.72 \\
\hline 2044 & 1.64 & 1.86 & 8.89 \\
\hline 1.11 & 5.43 & 5.86 & 3.98 \\
\hline 4.93 & 8.99 & 1.58 & 6.28 \\
\hline
\end{tabular}

$21 \quad$\begin{tabular}{|l|l|l|l|}
\hline 7.08 & 1.06 & 9.24 & 4.82 \\
\hline 7.01 & 5.16 & 8.60 & 8.06 \\
\hline 1.01 & 3.02 & 6.98 & 7.93 \\
\hline 5.15 & 6.42 & 4.48 & 3.90 \\
\hline
\end{tabular}




\section{PART C: Survey}

In this part you are asked to fill in a demographic and opinion survey.

1. Age

2. Sex:

$\square \mathrm{M} \square \mathrm{F}$

3. Degree:

Undergraduate $\square$ Graduate

4. Department:

Esomas $\square$ Management

5. Place of birth:

\section{Italy $\square$ Other}

6. Do you think your economic perspectives are better than your father's:

$\square$ Yes $\square$ No

Please, evaluate the following statements according to this scale:

- 1 : Strongly disagree

- 2: Disagree

- 3: Neither agree nor disagree

- 4: Agree

- 5: Strongly agree

7. Luck has a pivotal role in determining people's income
$1 \square 2 \square 3$
$3 \square \square 5$

8. Poor are trapped in their condition because of their lack of effort in looking for a job

\section{$1 \square 2 \square 3 \square 4 \square 5$}

9. How would you define your political ideology?

\section{Left $\square$ Centre-Left $\square$ Centre $\square$ Centre-Right $\square$ Right}

10. Did you vote in the last elections?

\section{Yes $\square$ No $\square$ Not allowed}

11. On a scale from 1 (the only priority is to defend individual liberty) to 10 (the only 
priority is to reach equality among members of the society) where would you place yourself?

Write a number from 1 to 10

12. How many economics courses did you attend? (e.g., Macroeconomics, Microeconomics, Public economics, Labor economics, Econometrics, Game Theory, ...)

\section{0-1 $\square$ 2-3 $\square$ 4-5 $\square$ 6-7 $\square$ over 7}

13. Did you find the experiment interesting?

$\square$ Yes $\square$ No

14. Did you attend any lesson today?

Yes $\square$ No

15. Did you have any difficulties in understanding the instructions?.

$$
\text { Yes } \square \text { No }
$$

16. How do you grade the degree of difficulty of the exercises?

Very Easy $\square$ Easy $\square$ Not easy nor Hard $\square$ Hard $\square$ Very Hard

17. Did you predict correctly the number of exercises you were able to solve?

Underestimated $\square$ Yes $\square$ Overestimated 
Table A1. Summary statistics of the variables used in the regression analysis $(N=37)$

\begin{tabular}{|c|c|c|c|c|}
\hline & Mean & St. Dev. & Min & Max \\
\hline \multicolumn{5}{|l|}{ Dependent variable } \\
\hline RISK_LOVE & 0.25 & 0.28 & 0 & 1 \\
\hline \multicolumn{5}{|l|}{ Main regressors } \\
\hline UNCERTAINTY & 0.46 & 0.51 & 0 & 1 \\
\hline RISK_LOVE & 9.46 & 3.70 & 3 & 16 \\
\hline UNCERTAINTY*RISK_LOVE & 4.54 & 5.66 & 0 & 16 \\
\hline EFFORT & 12.00 & 6.98 & 2 & 25 \\
\hline \multicolumn{5}{|l|}{ Demographic controls } \\
\hline$F E M A L E$ & 0.57 & 0.50 & 0 & 1 \\
\hline$A G E$ & 21.84 & 2.09 & 18 & 26 \\
\hline$I T A L I A N$ & 0.95 & 0.23 & 0 & 1 \\
\hline \multicolumn{5}{|l|}{ Students' characteristics } \\
\hline UNDER_GRADUATE & 0.65 & 0.48 & 0 & 1 \\
\hline$E C O N \_D E P T$ & 0.35 & 0.48 & 0 & 1 \\
\hline$E C O N \_E X A M S$ & 4.18 & 2.68 & 0.5 & 7.5 \\
\hline \multicolumn{5}{|l|}{ Cultural factors } \\
\hline BETTER_FATHER & 0.70 & 0.46 & 0 & 1 \\
\hline SUCCESS_LUCK & 3.54 & 0.90 & 1 & 5 \\
\hline POORS_TRAP & 2.43 & 1.09 & 1 & 4 \\
\hline
\end{tabular}

